\title{
Heart rate response during a simulated Olympic boxing match is predominantly above ventilatory threshold 2: a cross sectional study
}

This article was published in the following Dove Press journal:

Open Access Journal of Sports Medicine

9 July 2013

Number of times this article has been viewed

\author{
Claudio Andre Barbosa de \\ Lira' \\ Luiz Fernando Peixinho- \\ Pena $^{2}$ \\ Rodrigo Luiz Vancini ${ }^{1,2}$ \\ Rafael Júlio de Freitas \\ Guina Fachina ${ }^{3,4}$ \\ Alexandre Aparecido de \\ Almeida $^{2}$ \\ Marília dos Santos Andrade 2 \\ Antonio Carlos da Silva ${ }^{2}$ \\ 'Setor de Fisiologia Humana e do \\ Exercício, Universidade Federal de \\ Goiás (UFG), Câmpus Jataí, Jataí, \\ GO, Brazil; ; Departamento de \\ Fisiologia, Universidade Federal de \\ São Paulo (UNIFESP), São Paulo, SP, \\ Brazil; ${ }^{3}$ Departamento de Ciência \\ do Esporte, Faculdade de Educação \\ Física (FEF), Universidade Estadual \\ de Campinas (UNICAMP), Campinas, \\ Brazil; ${ }^{4}$ Confederação Brasileira de \\ Basketball (CBB), Rio de Janeiro, \\ Brazil
}

Correspondence: Claudio Andre Barbosa de Lira

Setor de Fisiologia Humana e do Exercício, Universidade Federal de Goiás (UFG), Câmpus Jataí; Rod BR 364, km 192, Parque Industrial, 3800, CP 03, 7580 I-6I5, Jataí, GO, Brazil Tel +55 643606830 I

Email andre.claudio@gmail.com
Abstract: The present study aimed to describe heart rate (HR) responses during a simulated Olympic boxing match and examine physiological parameters of boxing athletes. Ten highly trained Olympic boxing athletes (six men and four women) performed a maximal graded exercise test on a motorized treadmill to determine maximal oxygen uptake $\left(52.2 \mathrm{~mL} \cdot \mathrm{kg}^{-1} \cdot \mathrm{min}^{-1} \pm 7.2 \mathrm{~mL} \cdot \mathrm{kg}^{-1} \cdot \mathrm{min}^{-1}\right)$ and ventilatory thresholds 1 and 2 . Ventilatory thresholds 1 and 2 were used to classify the intensity of exercise based on respective HR during a boxing match. In addition, oxygen uptake $\left(\dot{V}_{2}\right)$ was estimated during the match based on the $\mathrm{HR}$ response and the $\mathrm{HR}-\dot{V} \mathrm{O}_{2}$ relationship obtained from a maximal graded exercise test for each participant. On a separate day, participants performed a boxing match lasting three rounds, 2 minutes each, with a 1-minute recovery period between each round, during which $\mathrm{HR}$ was measured. In this context, $\mathrm{HR}$ and $\dot{V} \mathrm{O}_{2}$ were above ventilatory threshold 2 during 219.8 seconds \pm 67.4 seconds. There was an increase in $\mathrm{HR}$ and $\dot{V} \mathrm{O}_{2}$ as a function of round (round $3<$ round $2<$ round $1, P<0.0001$ ). These findings may direct individual training programs for boxing practitioners and other athletes.

Keywords: heart rate, physiological profile, intermittent exercise, combat sports, boxing

\section{Introduction}

Boxing is a combat sport in which athletes try to strike and/or defend themselves from the attacks of their opponents. Matches are characterized by dynamic phases of short duration, which involve almost all muscle groups in complex movements characterized by short phases of maximal and/or supramaximal effort intensity, which lead to rapid accelerations and decelerations of body segments. ${ }^{1}$

To obtain an understanding of the physiological capacities underlying boxing performance, it would be useful to know the cardiovascular demand and the degree of recruitment of anaerobic metabolism during a match. These physiological variables would provide benchmarks for improving and monitoring athlete training regimens. ${ }^{2,3} \mathrm{In}$ addition, it could provide a basis for athletic performance strategies, as it would enable one to identify an athlete's potentials and limitations. ${ }^{4}$ Heart rate (HR) monitoring offers the opportunity to directly and easily evaluate the physiological profile of disciplinespecific performance and inexpensively evaluate the physiological demands. ${ }^{5}$ However, few studies in the literature have reported on the physiological demands of combat sports. ${ }^{1,6-9}$ In this context, maximal graded exercise testing is commonly employed to determine physiological response to exercise. Maximum oxygen uptake ( $\dot{V} \mathrm{O}_{2}$ max $)$ of an individual, which serves as a good marker for aerobic fitness, can be achieved during an exhaustive exercise test. Furthermore, graded maximal exercise testing allows for 
the determination of ventilatory thresholds (first ventilatory threshold $\left[\mathrm{VT}_{1}\right]$ and second ventilatory threshold $\left.\left[\mathrm{VT}_{2}\right]\right)$. $\mathrm{VT}_{1}$ corresponds to the break point in the plot of carbon dioxide production $\left(\dot{V} \mathrm{CO}_{2}\right)$ as a function of oxygen uptake $\left(\dot{V} \mathrm{O}_{2}\right)$. At that point, the ventilatory equivalent for $\mathrm{O}_{2}\left(\dot{V} E / \dot{V} \mathrm{O}_{2}\right)$ increases without an increase in the ventilatory equivalent for $\mathrm{CO}_{2}\left(\dot{V} E / \dot{V} \mathrm{CO}_{2}\right) . \mathrm{VT}_{2}$ is located between $\mathrm{VT}_{1}$ and $\dot{V} \mathrm{O}_{2}$ max, when $\dot{V} E / \dot{V} \mathrm{CO}_{2}$ starts to increase as $\dot{V} E / \dot{V} \mathrm{O}_{2}$ continues to increase. In practical terms, $\mathrm{VT}_{1}$ and $\mathrm{VT}_{2}$ can be used to prescribe exercise and to classify exercise intensity.

Because the popularity of combat sports practice is increasing, ${ }^{6,10,11}$ research into the physiological profile of these sports is necessary. Therefore, the aims of this study were to investigate physiological parameters of amateur boxers and to describe HR responses during a simulated boxing match. Also, the study compared HR responses during a simulated boxing match with those of $\mathrm{HR}$ associated with $\mathrm{VT}_{1}$ and $\mathrm{VT}_{2}$ attained during a maximal graded exercise test.

\section{Methods}

\section{Participants}

Ten highly trained boxing athletes (six men [two junior and four senior] and four women [two junior and two senior]) were recruited from local boxing teams located in São Paulo, Brazil. The age and anthropometrical characteristics of the participants are presented in Table 1. Each participant's height and weight were measured to the nearest $0.1 \mathrm{~cm}$ and $0.1 \mathrm{~kg}$, respectively. Skinfold thicknesses were obtained to estimate body fat percentage. Skinfold measurements were taken from seven sites on the right side of the body: triceps, subscapular, suprailiac, chest, abdomen, thigh, and midaxillary using a Lange skinfold caliper (Cambridge Scientific Industries, Inc, MD, USA). All skinfold measurements were carried out by the same examiner (to avoid inter examiner variability), who was previously trained and experienced in the use of skinfold calipers. Duplicate measurements were obtained, and the mean recorded value was used to determine body density. ${ }^{12}$ The Jackson and Pollock equation ${ }^{13}$ was used for male athletes, and the

Table I Characteristics of the boxing athletes

\begin{tabular}{lccc}
\hline & $\begin{array}{l}\text { Female athletes } \\
(\mathbf{n = 4 )}\end{array}$ & $\begin{array}{l}\text { Male athletes } \\
(\mathbf{n}=\mathbf{6})\end{array}$ & $\begin{array}{l}\text { Total } \\
(\mathbf{n}=10)\end{array}$ \\
\hline Age (years) & $17.7 \pm 1.7$ & $18.0 \pm 2.0$ & $17.9 \pm 1.8$ \\
Height $(\mathrm{cm})$ & $164.3 \pm 7.7$ & $173.4 \pm 7.5$ & $169.7 \pm 8.5$ \\
Body mass $(\mathrm{kg})$ & $61.2 \pm 6.6$ & $65.9 \pm 12.2$ & $64.0 \pm 10.1$ \\
Body fat (\%) & $22.0 \pm 3.5$ & $12.7 \pm 5.3$ & $16.4 \pm 6.5$ \\
\hline
\end{tabular}

Note: Data are presented as the means \pm standard deviation. equation formulated by Jackson et $\mathrm{al}^{14}$ was used for the female athletes. Body density values were then converted to body fat percentage using the Siri equations. ${ }^{15}$

All athletes trained five times a week in 2.5 hour sessions and had accumulated more than 2 years of training and competition. Their training focused on the development of technical and tactical skills that were specific to the sport of boxing and on the improvement of match-related fitness. All experimental procedures were approved by the University Human Research Ethics Committee and conformed to the principles outlined in the Declaration of Helsinki. All participants signed informed consent forms prior to participating in the study. For those participants under 18 years of age, written informed consent was signed by parents or guardians. All athletes were highly motivated to participate in the study and familiar with all testing methods. Participants continued their regular training programs and were requested, with their coaches consent, to refrain from strenuous workouts on the day before the test.

\section{Baseline medical examinations}

Before the beginning of the experimental procedures, each participant came to the laboratory for anamnesis and a physical examination to assess their health. These tests did not reveal any abnormalities that could contraindicate the participants' inclusion in the study.

\section{Experimental procedures}

Each participant reported to the laboratory on two separate occasions. During the first session, a maximal graded exercise test was administrated to determine $\mathrm{VT}_{1}, \mathrm{VT}_{2}$ and $\dot{V} \mathrm{O}_{2} \max$, as well as their associated running velocities and HR. In the second visit to the laboratory, the participants performed a simulated boxing match. A period of at least 48 hours separated the two laboratory visits, and all experimental procedures were completed within a 2 -week period. All participants were instructed to refrain from eating 2 hours before laboratory visits and to abstain from caffeine, alcohol, and strenuous physical activity on each test day. Water intake was allowed ad libitum. The temperature and relative humidity in the testing laboratory ranged from $21^{\circ} \mathrm{C}-23^{\circ} \mathrm{C}$ and $55 \%-65 \%$, respectively, for all trials. We carried out our experiments in both the morning and afternoon. However, for each participant, the maximal graded exercise test and simulated boxing match were conducted at the same time of day.

Prior to performing the maximal graded exercise test, participants were given a standardized set of instructions 
explaining the test. On completion of these preliminary procedures, each participant underwent an incremental maximal exercise test on a motorized treadmill (Super ATL, Inbrasport Ltd, São Geraldo, MG, Brazil) with 0\% slope. The schedule of this test consisted of a 5-minute warm-up period at $6 \mathrm{~km} \cdot \mathrm{h}^{-1}$, and then the initial speed was adjusted to $7 \mathrm{~km} \cdot \mathrm{h}^{-1}$, followed by progressive increases of the treadmill speed at a rate of $1 \mathrm{~km} \cdot \mathrm{h}^{-1}$ every minute until participant exhaustion. During the exercise testing, participants were verbally encouraged to exercise for as long as possible. Respiratory gas samples of each breath were analyzed using a gas analyzer (K4b2, COSMED, Rome, Italy). Before each test, the gas analyzer was calibrated using gas of a known concentration $\left(16 \%\right.$ of $\mathrm{O}_{2}$ and $4 \%$ of $\mathrm{CO}_{2}$; White Martins, Rio de Janeiro, Brazil), and the flow meter was calibrated using a 3 L syringe (Hans Rudolph, Inc, Shawnee, KS, USA). A Polar Electronics HR monitor (Polar Electronics, FS1, Kempele, Oulu, Finland) was used to record in real-time, as the metabolic system utilized in this study was equipped with a receiver unit, able to capture the signal.

The following data (averaged over 20 seconds) were obtained: $\dot{V} \mathrm{O}_{2}\left(\mathrm{~mL} \cdot \mathrm{min}^{-1}\right)$ at standard temperature $\left(0^{\circ} \mathrm{C}\right)$ and barometric pressure at sea level, $\dot{V} \mathrm{CO}_{2}\left(\mathrm{~mL} \cdot \min ^{-1}\right)$ at standard temperature $\left(0^{\circ} \mathrm{C}\right)$ and barometric pressure at sea level, respiratory exchange ratio (RER), minute ventilation $\dot{V} E\left(\mathrm{~L} \cdot \mathrm{min}^{-1}\right)$ at body temperature and pressure saturated, respiratory rate (breaths per minute $[\mathrm{bpm}]$ ), ventilatory equivalents for $\mathrm{O}_{2}$ and $\mathrm{CO}_{2}\left(\dot{V} E / \dot{V} \mathrm{O}_{2}\right.$ and $\dot{V} E /$ $\dot{V} \mathrm{CO}_{2}$, respectively), expired fractions of $\mathrm{O}_{2}$ and $\mathrm{CO}_{2}(\%)$ and HR (beats per minute $[\mathrm{bpm}]$ ). Peak treadmill velocity was defined as the last achieved running speed sustained for at least 30 seconds. $\dot{V} \mathrm{O}_{2}$ max was always defined as the highest 20 -second averaged $\dot{V} \mathrm{O}_{2}$ value with inclusion criteria consistent with conventional guidelines for $\dot{V} \mathrm{O}_{2} \max (\mathrm{eg}$, an inability to sustain the workload, relative HR $>95 \%$ predicted for their age, RER at maximal exercise $>1.1$, and $\dot{V} \mathrm{O}_{2}$ plateau [the point at which $\dot{V} \mathrm{O}_{2}$ increases less than $150 \mathrm{~mL} \cdot \mathrm{min}^{-1}$ for a given increase in workload]). Ventilatory thresholds were assessed using established criteria. ${ }^{16}$ Briefly, $\mathrm{VT}_{1}$ corresponds to the break point in the plot of $\dot{V} \mathrm{CO}_{2}$ as a function of $\dot{V} \mathrm{O}_{2}$. At that point, $\dot{V} E / \dot{V} \mathrm{O}_{2}$ increases without an increase in $\dot{V} E / \dot{V} \mathrm{CO}_{2} . \mathrm{VT}_{2}$ was located between $\mathrm{VT}_{1}$ and $\dot{V} \mathrm{O}_{2}$ max, when $\dot{V} E / \dot{V} \mathrm{CO}_{2}$ starts to increase and $\dot{V} E / \dot{V} \mathrm{O}_{2}$ continues to increase. $\mathrm{VT}_{1}$ and $\mathrm{VT}_{2}$ were determined independently by three experienced investigators. If agreement between two out of three investigators was not achieved, VT was determined by consensus. To determine the $\dot{V} \mathrm{O}_{2}$ and $\dot{V} E$ at $\mathrm{VT}_{1}$ and $\mathrm{VT}_{2}$, the average of the last 20 seconds of each corresponding level was used. In practical terms, ventilatory thresholds represent points that can be used to classify the intensity of aerobic exercise.

Finally, the second visit to the laboratory was used to apply a simulation of a boxing match. This simulation was conducted in a boxing ring $(6 \mathrm{~m} \times 6 \mathrm{~m})$ and was accompanied by a referee with extensive experience in boxing. The participants were instructed to prepare themselves as they usually would for an official match. Participants performed a 10 minute warm up, which consisted of standard boxing movements, and then rested on a bench until HR returned to the pre-exercise level. The match consisted of three rounds, each 2 minutes long, with 1 minute of recovery between them. During each recovery period, the participant sat on a bench and was allowed to drink water. To simulate a match as realistically as possible, a sparring partner with a skilled trainer was enlisted. This partner had the same body mass, height, sex, ability, and boxing experience as the evaluated athlete and was aware of his or her participation in a scientific study. Additionally, the athletes were verbally encouraged by their coaches throughout the match to perform as well as possible. After the 1 minute recovery period following the last round, an additional 10 minute period of further recovery was allowed (final recovery). HR was recorded before, during (including rest periods between rounds), and after the simulated boxing match. HR registers (5-s average HR value) were monitored by a commercially available telemetric system (Suunto Team Pod, Suunto, Vantaa, Finland), which allowed us to monitor heart rate in real time. HR recorded during a simulated boxing match was compared with HRs corresponding to $\mathrm{VT}_{1}$ and $\mathrm{VT}_{2}$. In addition, $\dot{V} \mathrm{O}_{2}$ was estimated during the match for each participant based on the HR response and the $\mathrm{HR}-\dot{V} \mathrm{O}_{2}$ relationship for each participant as determined from maximal graded exercise test results. Despite the indirect $\dot{V} \mathrm{O}_{2}$ estimation by $\mathrm{HR}-\dot{V} \mathrm{O}_{2}$ relationship obtained from maximal graded exercise test, this strategy is considered valid for intermittent activities. ${ }^{17-19}$

\section{Statistical analysis}

All variables presented normal distributions $(P>0.05)$ according to Kolmogorov-Smirnov tests. Therefore, the differences between rounds were analyzed by one-way ANOVA (analysis of variance) for repeated measures. When significant modifications were found, the Tukey post hoc procedure was performed to localize the difference. Pearson linear regression analysis was used to determine any potential linear relationships between variables. All statistical analyses were performed with GraphPad Prism 5.0 (San Diego, CA, 
USA). The level of significance was $P<0.05$. Data are shown as the means \pm standard deviations.

\section{Results}

Data for the maximal graded exercise test are shown in Table 2. All participants $(\mathrm{n}=10)$ attained age-predicted maximum HR, RER $>1.1$, fatigue and $\dot{V} \mathrm{O}_{2}$ plateau (when $\dot{V} \mathrm{O}_{2}$ increased less than $150 \mathrm{~mL} \cdot \min ^{-1}$ for a given increase in workload). The $\dot{V} \mathrm{O}_{2} \max$ of the athletes was $52.2 \mathrm{~mL} \cdot \mathrm{kg}^{-1} \cdot \mathrm{min}^{-1} \pm 7.2 \mathrm{~mL} \cdot \mathrm{kg}^{-1} \cdot \mathrm{min}^{-1}$ and was reached at a treadmill speed of $15.7 \mathrm{~km} \cdot \mathrm{h}^{-1} \pm 2.5 \mathrm{~km} \cdot \mathrm{h}^{-1}$, with a maximum heart rate $\left(\mathrm{HR}_{\max }\right)$ of $193 \mathrm{bpm} \pm 7 \mathrm{bpm} . \mathrm{VT}_{1}$ and $\mathrm{VT}_{2}$ were detected in all cases. The $\dot{V} \mathrm{O}_{2}$ levels at $\mathrm{VT}_{1}$ and $\mathrm{VT}_{2}$ were $40.5 \mathrm{~mL} \cdot \mathrm{kg}^{-1} \cdot \mathrm{min}^{-1} \pm 5.9 \mathrm{~mL} \cdot \mathrm{kg}^{-1} \cdot \mathrm{min}^{-1}$ and $47.5 \mathrm{~mL} \cdot \mathrm{kg}^{-1} \cdot \mathrm{min}^{-1} \pm 6.0 \mathrm{~mL} \cdot \mathrm{kg}^{-1} \cdot \mathrm{min}^{-1}$, respectively, andwere reached at treadmill speeds of $11.0 \mathrm{~km} \cdot \mathrm{h}^{-1} \pm 1.4 \mathrm{~km} \cdot \mathrm{h}^{-1}$ and $13.6 \mathrm{~km} \cdot \mathrm{h}^{-1} \pm 1.8 \mathrm{~km} \cdot \mathrm{h}^{-1}$, with HRs of $167 \mathrm{bpm} \pm 9 \mathrm{bpm}$ and $181 \mathrm{bpm} \pm 6 \mathrm{bpm}$, respectively.

The HR behavior during the simulated boxing match is shown in Table 3 . There was a round effect $(P<0.0001)$ : the highest $\mathrm{HR}$ and percent of $\mathrm{HR}_{\max }$ were attained in round three and were 4.7\% $(P=0.0008)$ and 5.5\% $(P=0.0009)$ higher than those attained in round one, respectively. The average $\mathrm{HR}$ in round two and percent of $\mathrm{HR}_{\max }$ attained were both $4.5 \%$ ( $P<0.0001$ for both) higher than those attained in round one. The average HR in round three and the respective percent of $\mathrm{HR}_{\text {max }}$ attained were $6.3 \%$ and $5.5 \%$ ( $P<0.0001$ for both) higher than those obtained in round one, respectively. In round one, the average time spent at a HR below the $\mathrm{VT}_{1}$ level was 22.5 seconds \pm 23.9 seconds, time spent at a HR between the $\mathrm{VT}_{1}$ and $\mathrm{VT}_{2}$ levels was 47.9 seconds \pm 35.5 seconds, and time spent at a HR above the $\mathrm{VT}_{2}$ level was 49.6 seconds \pm 42.7 seconds. In round two, the average time spent below the $\mathrm{VT}_{1} \mathrm{HR}$ was 9.0 seconds \pm 7.5 seconds, between the $\mathrm{VT}_{1}$ and $\mathrm{VT}_{2} \mathrm{HRs}$

Table 2 Physiological parameter characterization obtained by graded exercise maximal test

\begin{tabular}{lccl}
\hline & $\mathbf{V T}_{1}(\mathbf{n}=1 \mathbf{0})$ & $\mathbf{V T}_{2}(\mathbf{n}=1 \mathbf{0})$ & $\begin{array}{l}\text { Maximal } \\
\text { exercise } \\
(\mathbf{n}=10)\end{array}$ \\
\hline$\dot{\mathrm{VO}}{ }_{2}\left(\mathrm{~mL} \cdot \mathrm{kg}^{-1} \cdot \mathrm{min}^{-1}\right)$ & $40.5 \pm 5.9$ & $47.5 \pm 6.0$ & $52.2 \pm 7.2$ \\
$\% \dot{\mathrm{VO}}_{2} \max$ & $77.8 \pm 6.8$ & $91.3 \pm 5.5$ & $\mathrm{~N} / \mathrm{A}$ \\
$\mathrm{HR}(\mathrm{bpm})$ & $167 \pm 9$ & $181 \pm 6$ & $193 \pm 7$ \\
$\%$ attained $\mathrm{HR}_{\max }$ & $86 \pm 4$ & $94 \pm 3$ & $\mathrm{~N} / \mathrm{A}$ \\
Velocity $\left(\mathrm{km} \cdot \mathrm{h}^{-1}\right)$ & $11.0 \pm 1.4$ & $13.6 \pm 1.8$ & $\mathrm{I} 5.7 \pm 2.5$ \\
\hline
\end{tabular}

Note: Data are presented as the means \pm standard deviation.

Abbreviations: bpm, beats per minute; $\mathrm{HR}$, heart rate; $\mathrm{HR}_{\max }$, maximum heart rate; N/A, not applicable; $\dot{V O}_{2}$, oxygen uptake; VT, ventilator threshold. was 21.0 seconds \pm 7.8 seconds and above the $\mathrm{VT}_{2}$ HR was 90.0 seconds \pm 12.9 seconds. In round three, the mean time spent below the $\mathrm{VT}_{1}$ HR was 7.0 seconds \pm 16.0 seconds and 5.6 seconds \pm 13.0 seconds, between the $\mathrm{VT}_{1}$ and $\mathrm{VT}_{2}$ was $14.0 \pm 6.0$ and above the $\mathrm{VT}_{2}$ was 99.0 seconds \pm 14.0 seconds. It is noteworthy that there was a progressive decrease in the amount of time below the $\mathrm{VT}_{1} \mathrm{HR}$ and, consequently, a gradual increase of the time spent above the $\mathrm{VT}_{2} \mathrm{HR}$. Similar behavior was found in estimated $\dot{V} \mathrm{O}_{2}$ during the simulated boxing match (Table 4).

There was a round effect for HR recovery $(P<0.0001)$ : HR measured immediately at the end of the round was significantly different between rounds (Table 5) (round three $>$ round two $>$ round one). Regarding HR after 60 seconds of recovery, there was a significant difference only between round one and round two $(P=0.0235)$. HR recovery $[\Delta(\%)]$ was $13 \%-19 \%$ for all rounds, without differences between them $(P=0.1034)$. In absolute values, the decrease in HR was $35 \mathrm{bpm} \pm 23 \mathrm{bpm}, 26 \mathrm{bpm} \pm 11 \mathrm{bpm}$, and $32 \mathrm{bpm} \pm 13 \mathrm{bpm}$, respectively, for round one, round two, and round three, without differences between them $(P=0.1229)$.

There were no significant correlations between aerobic variables and $\Delta(\%) . \dot{V} \mathrm{O}_{2} \max$ and its $\Delta(\%)(r=0.5432$ and $P=0.1047), \dot{V} \mathrm{O}_{2}$ atVT 1 and its $\Delta(\%)(r=0.5336$ and $P=0.1122)$, $\dot{V} \mathrm{O}_{2}$ at $\mathrm{VT}_{2}$ and its $\Delta(\%)(r=0.6307$ and $P=0.0506), \dot{V} \mathrm{O}_{2}$ $\max$ and its $\Delta(\%)(r=0.5227$ and $P=0.1211), \mathrm{VT}_{1}$ and its $\Delta(\%)(r=0.5157$ and $P=0.1271)$ and $\mathrm{VT}_{2}$ and its $\Delta(\%)$ ( $r=0.5026$ and $P=0.1387$ ) were all not correlated with HR recovery.

\section{Discussion}

The primary aims of the present study were to describe the behavior of HR during a simulated Olympic boxing match and characterize the intensity of the modality and physiological profile of these athletes. The main finding of this descriptive study was that the average intensity of a simulated boxing match was very severe, as an appreciable percentage $(\sim 60 \%)$ of the exercise bout occurred at an intensity greater than $\mathrm{VT}_{2}$, based on maximal HR (above $85 \%$ of the age-predicted maximal HR).

The findings of this study show that the percentage of the simulated boxing match at exercise intensities greater than $\mathrm{VT}_{1}$ was much higher than routinely observed in athletes during spontaneous training, ${ }^{20}$ although it is within the range of individual high-intensity training bouts in athletes. ${ }^{21}$

Wushu, Chito Ryu Seisan Kata, taekwondo, and Muay Thai are also combat sports that present elevated 
Table 3 Heart rate and time (expressed as relative percentage) in each metabolic zone, defined as below VT, between the VT, and $\mathrm{VT}_{2}$, and above the $\mathrm{VT}_{2}$ during a simulated boxing match $(\mathrm{n}=10)$

\begin{tabular}{|c|c|c|c|c|c|}
\hline & Round I & Round 2 & Effect size & Round 3 & Effect size \\
\hline Highest HR (bpm) & $190 \pm 8$ & $194 \pm 6$ & - & $199 \pm 5^{a}$ & -0.56 \\
\hline$\%$ predicted $\mathrm{HR}_{\max }$ & $98 \pm 4$ & $101 \pm 3$ & - & $103 \pm 2^{\mathrm{a}}$ & -0.62 \\
\hline Average HR (bpm) & $175 \pm 11$ & $183 \pm 6^{a}$ & -0.41 & $186 \pm 7^{a}$ & -0.51 \\
\hline$\%$ attained $\mathrm{HR}_{\max }$ & $91 \pm 5$ & $95 \pm 3^{a}$ & -0.43 & $96 \pm 2^{\mathrm{a}}$ & -0.55 \\
\hline Time below to $\mathrm{HR}$ at $\mathrm{VT}$, (\%) & $19.0 \pm 20.0$ & $7.0 \pm 6.0^{\mathrm{a}}$ & 0.37 & $5.6 \pm 13.0^{\mathrm{a}}$ & 0.37 \\
\hline $\begin{array}{l}\text { Time between to } H R \\
\text { at } V T_{1}-V_{2}(\%)\end{array}$ & $40.0 \pm 30.0$ & $18.0 \pm 6.0^{\mathrm{a}}$ & 0.45 & $1 \mathrm{l} .6 \pm 5 . \mathrm{I}^{\mathrm{a}}$ & 0.55 \\
\hline Time above to $\mathrm{HR}$ at $\mathrm{VT}_{2}(\%)$ & $41.0 \pm 36.0$ & $75.0 \pm 11.0^{\mathrm{a}}$ & -0.54 & $82.8 \pm 11.5^{\mathrm{a}}$ & -0.61 \\
\hline
\end{tabular}

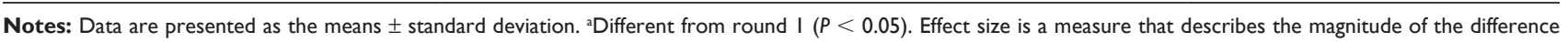
between two groups.

Abbreviations: bpm, beats per minute; $\mathrm{HR}$, heart rate; $\mathrm{HR}_{\max }$, maximum heart rate; $\mathrm{VT}$, ventilatory threshold.

intensities during matches. ${ }^{4,22-25}$ Bridge et a ${ }^{25}$ evaluated the HR responses of specific Taekwondo training activities practiced by experienced practitioners in a natural training environment and found that this sport stimulated the HR to reach $64.7 \%-81.4 \%$ of $\mathrm{HR}_{\max }$. Therefore, boxing, as with other combat sports, has a strong impact on cardiovascular and respiratory functions.

However, as an episodic training activity, the comparatively high intensity may be associated with an effective training response. In particular, results presented by Helgerud et $\mathrm{al}^{26}$ and Laursen et $\mathrm{al}^{27}$ have suggested that improving $\dot{V} \mathrm{O}_{2}$ max in already trained athletes, required training intensities which approached the intensity of $\dot{V} \mathrm{O}_{2}$ max. This could be a plausible explanation for the high $\dot{V} \mathrm{O}_{2}$ max observed in our athletes. Other studies of boxing and various combat sports have found similar values of $\dot{V} \mathrm{O}_{2}$ max. ${ }^{7,11,22}$

Another objective of the present study was to determine the aerobic physiological parameters of boxers. This is an important objective because the physiological profile is used to modify training programs and assist with individual competition strategies. For example, an athlete with a substantial maximal aerobic power (ie, high $\dot{V} \mathrm{O}_{2}$ $\max$ ) would be encouraged to maintain a high intensity of action during a match. On the other hand, an athlete with superior strength and anaerobic capacity might be more selective in the initiation of attacks ${ }^{28}$ and be more explosive in the implementation of boxing actions. In this study, we found that athletes presented high $\dot{V} \mathrm{O}_{2}$ max. In addition, the elevated $\% \mathrm{HR}_{\max }$ and $\% \dot{\mathrm{V}} \mathrm{O}_{2}$ max attained during simulated boxing matches indicates that anaerobic complementation is important to this sport. Similar findings have been demonstrated previously for karate and taekwondo athletes. ${ }^{7,24,29}$

Reinforcing the importance of aerobic metabolism for performance in boxing, Guidetti et $\mathrm{al}^{7}$ examined the relationship between ranking in boxing competition performance and some aerobic physiological parameters in eight middleweight-class elite Italian boxing athletes. A Spearman rho correlation analysis revealed that the $\dot{V} \mathrm{O}_{2}$ at the individual anaerobic threshold $\left(46.0 \mathrm{~mL} \cdot \mathrm{kg}^{-1} \cdot \mathrm{min}^{-1} \pm 4.2 \mathrm{~mL} \cdot \mathrm{kg}^{-1} \cdot \min ^{-1}, r=0.91\right)$ and the hand-grip strength $(58.2 \mathrm{~kg} \pm 6.9 \mathrm{~kg}, r=0.87)$ were highly correlated $(P<0.01)$ with boxing competition ranking. $\dot{V} \mathrm{O}_{2} \max \left(57.5 \mathrm{~mL} \cdot \mathrm{kg}^{-1} \cdot \mathrm{min}^{-1} \pm 4.7 \mathrm{~mL} \cdot \mathrm{kg}^{-1} \cdot \mathrm{min}^{-1}\right.$, $r=0.81)$ and wrist girth $(17.6 \mathrm{~cm} \pm 0.6 \mathrm{~cm}, r=0.78)$ were moderately $(P<0.05)$ correlated. These data suggest

Table 4 Estimated oxygen uptake and time (expressed as relative percentage) in each metabolic zone, defined as below $\mathrm{VT}_{\text {, }}$, between the $\mathrm{VT}_{1}$ and $\mathrm{VT}_{2}$, and above the $\mathrm{VT}_{2}$ during a simulated boxing match $(\mathrm{n}=10)$

\begin{tabular}{|c|c|c|c|c|c|}
\hline & Round I & Round 2 & Effect size & Round 3 & Effect size \\
\hline Highest $\dot{V} \mathrm{O}_{2}\left(\mathrm{~mL} \cdot \mathrm{kg}^{-1} \cdot \mathrm{min}^{-1}\right)$ & $50.8 \pm 5.6$ & $52.6 \pm 5.2$ & - & $54.6 \pm 6.2^{\mathrm{a}}$ & -0.30 \\
\hline$\%$ attained $\mathrm{VO}_{2} \max$ & $99.3 \pm 7.0$ & $102.9 \pm 5.7$ & - & $106.6 \pm 5.6^{\mathrm{a}}$ & -0.50 \\
\hline Average $\dot{V} \mathrm{O}_{2}\left(\mathrm{~mL} \cdot \mathrm{kg}^{-1} \cdot \mathrm{min}^{-1}\right)$ & $44.2 \pm 7.2$ & $48.0 \pm 6.1^{\mathrm{a}}$ & -0.27 & $49.6 \pm 5.6^{\mathrm{a}}$ & -0.40 \\
\hline$\%$ attained $\dot{\mathrm{V}} \mathrm{O}_{2} \max$ & $86.9 \pm 8.3$ & $93.9 \pm 5.1^{\mathrm{a}}$ & -0.45 & $97.0 \pm 4.9^{\mathrm{a}}$ & -0.60 \\
\hline Time below to $\dot{\mathrm{V}} \mathrm{O}_{2}$ at $\mathrm{VT}_{1}(\%)$ & $16.0 \pm 13.9$ & $7.3 \pm 6.0^{\mathrm{a}}$ & 0.37 & $3.5 \pm 5.8^{\mathrm{a}}$ & 0.50 \\
\hline Time between to $\dot{\mathrm{V}} \mathrm{O}_{2}$ at $\mathrm{VT} \mathrm{T}_{1}-\mathrm{VT}_{2}(\%)$ & $51.7 \pm 28.6$ & $22.3 \pm 9.9^{a}$ & 0.56 & $17.5 \pm 9.7^{\mathrm{a}}$ & 0.62 \\
\hline Time above to $\dot{\mathrm{V}} \mathrm{O}_{2}$ at $\mathrm{VT}_{2}(\%)$ & $32.2 \pm 34.1$ & $70.4 \pm 14.4^{\mathrm{a}}$ & -0.60 & $79.0 \pm 14.0^{\mathrm{a}}$ & -0.66 \\
\hline
\end{tabular}

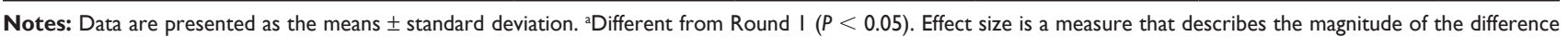
between two groups.

Abbreviations: $\mathrm{VO}_{2}$, oxygen uptake; $\mathrm{VT}$, ventilatory threshold. 
Table 5 Decrease in HR from 0-60 seconds after round as a percentage of HR measured immediately at the end of the round $(n=10)$

\begin{tabular}{lccccl}
\hline & Round I & Round 2 & $\begin{array}{l}\text { Effect } \\
\text { size }\end{array}$ & Round 3 & $\begin{array}{l}\text { Effect } \\
\text { size }\end{array}$ \\
\hline $\mathrm{HR}_{\text {osec }}$ & $187 \pm 6$ & $192 \pm 5^{\mathrm{a}}$ & $-0.4 \mathrm{I}$ & $195 \pm 6^{\mathrm{a}, \mathrm{b}}$ & $\begin{array}{l}-0.55 / \\
(\mathrm{bPm})\end{array}$ \\
$\mathrm{HR}_{60 \mathrm{sec}}$ & $152 \pm 25$ & $166 \pm 10^{\mathrm{a}}$ & -0.34 & $163 \pm 14$ & - \\
$(\mathrm{bpm})$ & & & & & -0.26 \\
$\Delta(\%)$ & $-18.8 \pm 12.7$ & $-13.3 \pm 5.6$ & - & $-16.4 \pm 7.0$ & - \\
\hline
\end{tabular}

Notes: Data are presented as the means \pm standard deviation. a Different from Round I $(P<0.05)$; b different from Round $2(P<0.05) . \Delta(\%)$ was calculated as percentage of peak $H R_{0 \text { sec }}:\left(H_{60 \text { sec }}-H_{0 \text { sec }}\right) / H R_{60 \text { sec }} \times 100$. Effect size is a measure that describes the magnitude of the difference between two groups.

Abbreviations: bpm, beats per minute; $\mathrm{HR}$, heart rate; $\mathrm{HR}_{\mathrm{0sec}}$, heart rate measured immediately at the end of the round; $H R_{60 \mathrm{sec}}$, heart rate measured after 60 seconds of recovery; $\mathrm{HR}_{\text {osec }}-\mathrm{HR}_{60 \mathrm{sec}}(\%)$, percentage of recovery between the end of the round and after 60 seconds of recovery.

that two basic factors are related to boxing performance: physical fitness, as indicated by individual anaerobic threshold and maximal oxygen uptake, and upper body muscular strength, as indicated by hand-grip strength (related to anaerobic metabolism).

Despite the development of lightweight, portable metabolic devices to measure physiological responses during an activity, one of the difficulties of working with boxing (and other combat sports) is measuring the $\dot{V} \mathrm{O}_{2}$ during a match. Another reason $\dot{V} \mathrm{O}_{2}$ was not measured in the current study was our intent to maintain the "ecological validity" of simulated matches. The term "ecological validity" in this setting refers specifically to the interaction of boxing athletes with their natural environment and practices. ${ }^{25}$ Therefore, we estimated the $\dot{V} \mathrm{O}_{2}$ during the simulated boxing match. We verified that $\dot{\mathrm{V}} \mathrm{O}_{2}$ attained during the matches reflected the high intensity of boxing, as mentioned above. Again, these results underscore the importance of a minimum of aerobic fitness for boxing athletes and suggest some guidelines for the intensity of training, in accordance with the literature. ${ }^{8}$

Increases in physiological variables $\left(\mathrm{V}_{2}\right.$ and $\left.\mathrm{HR}\right)$ were observed over the course of the simulated boxing match and similarly in other intermittent sport activities. In addition, indirect $\dot{V} \mathrm{O}_{2}$ estimation by HR- $\dot{V} \mathrm{O}_{2}$ relationship is commonly considered acceptable for intermittent activities. ${ }^{17-19}$ This indicates that there was a greater energy demand for the completion of high-intensity actions as sparing progressed. We suggest three factors that could be related to the increase in physiological demand during the match. First, athletes may have been under thermal stress due to protective garments. Second, the short rest periods between rounds (1 minute) did not allow sufficient time for physiological variables to decline. A third possibility is that each participant's competition strategy led to increased demand in each round. It is common for combat-sport athletes to save energy for the last period of the combat, when the most decisive attacks normally occur, resulting in an increase in the metabolic response during the last round. ${ }^{24,30}$

Finally, of particular interest in this study, was the ability of the athletes to recover their HR between rounds as analyzed through the relationships between aerobic variables $\left(\dot{V} \mathrm{O}_{2} \max , \mathrm{VT}_{1}\right.$, and $\left.\mathrm{VT}_{2}\right)$ and the decrease in $\mathrm{HR}$. We found no correlations between these variables. There are two explanations for this: First, in martial arts environments, HR overestimations have been attributed to the static nature of upper and lower limb movements or only to upper limb movements (small muscle mass), ${ }^{31,32}$ which seems plausible. ${ }^{33}$ However, HR overestimations may also be attributed to emotional factors or thermal stress (as mentioned above). Together, these factors can contribute to a failure of HR to show appreciable recovery between work intervals. ${ }^{34}$ Second, HR recovery following exercise is controlled by complex interactions between neural and humoral factors. ${ }^{35}$ In this context, systemic stress metabolite accumulation during postexercise recovery (eg, plasma epinephrine, lactate, $\mathrm{H}^{+}$, and inorganic phosphate $)^{36}$ might promote sympathetic activity via chemoreflex control of $\mathrm{HR}^{37}$ and, consequently, delay HR recovery. Buchheit et al ${ }^{38}$ compared the HR recovery response among children, adolescents, and adults, while also taking into account power output and the postexercise blood lactate concentration and acidosis. These authors showed that children experienced significantly faster HR recovery compared with their adolescent and adult counterparts. This apparent difference in HR recovery was associated with lower blood lactate and $\mathrm{H}^{+}$in children compared with adolescents and adults because children have an immature capacity for anaerobic metabolism. ${ }^{38}$ Although the concentration of lactate was not measured in this study, it is likely that our volunteers presented a high concentration of this blood metabolite because, as mentioned earlier, this activity is of high intensity and therefore requires a significant anaerobic contribution.

\section{Strengths and limitations of this study}

First, our sample contained female and male participants. There are obvious differences in physiological and morphological characteristics between sexes (Table 1 and 2). For instance, women have a lower lung volume, cardiac output, $\dot{V} \mathrm{O}_{2}$ max, and hemoglobin concentration as well as a greater body fat content compared to men. ${ }^{39,40}$ However, there 
is evidence that physiological responses to exercise are not different between sexes, especially when HR, blood lactate, and percentage of $\dot{V} \mathrm{O}_{2}$ max are analyzed during exercise. ${ }^{3}$ Therefore, cardiovascular and metabolic strain seems to be comparable between sexes for the investigated situation in the present study.

Second, only ten participants were enrolled in the study due to the difficulty of recruiting elite boxers. Attaining high participant numbers is an inherent challenge in studies that involve a specific population, such as elite athletes. Other studies dealing with combat sports have employed participant numbers similar to our study or fewer. ${ }^{3,424,29}$ Therefore, it is conceivable that the participants enrolled represent the typical amateur boxer.

Third, the fight was not recorded, so we were not able to assess movements performed by these boxers, such as highintensity offensive and defensive techniques, the distance covered by the athletes, and work/rest ratios. These variables may interfere with HR responses during a fight.

Notwithstanding these limitations, this study demonstrates that boxing involves a high demand on the cardiovascular system and aerobic system, as evidenced by values of HR corresponding to vigorous and very vigorous exercise. The same can be said of the estimated $\dot{V} \mathrm{O}_{2}$. Regarding whether aerobic fitness is an important determinant for the recovery of HR, this study found no statistically significant correlation between recovery of $\mathrm{HR}$ and $\dot{V} \mathrm{O}_{2}$ max. It appears that in boxing, undertaking specific training to improve aerobic capacity seems to be necessary for the rapid recovery of HR between rounds. In summary, the present investigation provides baseline physiological data that can be used in the prescription of individual training programs for boxing athletes. These data are also important to coaches and can contribute to competition strategies for individual athletes and in individual matches. Furthermore, training protocols should include exercises that train both aerobic and anaerobic energy pathways, and amateur boxing could be used to develop aerobic fitness.

\section{Acknowledgments}

We are grateful to the directors of the Olympic Center of Research and Training (Prefeitura Municipal de São Paulo, Brazil) and Mr Messias Gomes for their technical assistance. We also thank all the athletes who volunteered to participate in this study. CABL received a fellowship from the Coordenação de Aperfeiçoamento de Pessoal de Nível Superior (CAPES [Coordenação de Aperfeiçoamento de Pessoal de Nível Superior], Brazil).
This work was supported by the Financiadora de Estudos e Projetos (FINEP, Brazil).

Author contributions to this work were as follow: CABL and LFP-P: study concept and design, data acquisition, analysis, interpretation, and manuscript preparation; AAA and RLV: data analysis, interpretation, and manuscript preparation; MSA and RJFGF: data acquisition and critical revision of the manuscript; ACS: study concept and design, data analysis, interpretation, and critical revision of the manuscript. CABL and LFP-P contributed equally to this work and may be cited in interchangeable order.

Ethics approval was granted by the Committee of Ethics in Research from UNIFESP (Federal University of São Paulo).

\section{Disclosure}

No commercial party having a direct financial interest in the results of the research presented in this article has or will confer a benefit upon the authors or upon any organization with which the authors are associated. There is no additional data available from this study. The authors report no conflicts of interest in this work.

\section{References}

1. Kravitz L, Greene L, Burkett Z, Wongsathikun J. Cardiovascular response to punching tempo. J Strength Cond Res. 2003;17(1):104-108.

2. Heller J. Energy cost and cardiorespiratory demands of nunchaku exercise. J Sports Med Phys Fitness. 2000;40(3):217-222.

3. Faude O, Meyer T, Rosenberger F, Fries M, Huber G, Kindermann W. Physiological characteristics of badminton match play. Eur J Appl Physiol. 2007;100(4):479-485.

4. Ribeiro J, de Castro B, Rosa C, Baptista R, Oliveira A. Heart rate and blood lactate responses to changquan and daoshu forms of modern Wushu. J Sports Sci Med. 2006;5:1-4.

5. Meyer T, Davison RC, Kindermann W. Ambulatory gas exchange measurements - current status and future options. Int J Sports Med. 2005;26(Suppl 1):S19-S27.

6. Bellinger B, St Clair Gibson A, Oelofse A, Oelofse R, Lambert M. Energy expenditure of a noncontact boxing training session compared with submaximal treadmill running. Med Sci Sports Exerc. 1997;29(12): 1653-1656.

7. Guidetti L, Musulin A, Baldari C. Physiological factors in middleweight boxing performance. J Sports Med Phys Fitness. 2002;42(3): 309-314.

8. Chatterjee P, Banerjee AK, Majumdar P, Chatterjee P. Energy expenditure in women boxing. Kathmandu Univ Med J (KUMJ). 2006; 4(3):319-323.

9. Arseneau E, Mekary S, Léger LA. $\dot{V} O_{2}$ requirements of boxing exercises. J Strength Cond Res. 2011;25(2):348-359.

10. Imamura H, YoshimuraY, Uchida K, TanakaA, Nishimura S, NakazawaAT. Heart rate, blood lactate responses and ratings of perceived exertion to 1,000 punches and 1,000 kicks in collegiate karate practitioners. Appl Human Sci. 1997;16(1):9-13.

11. Heller J, Peric T, Dlouhá R, Kohlíková E, Melichna J, Nováková H. Physiological profiles of male and female taekwon-do (ITF) black belts. J Sports Sci. 1998;16(3):243-249. 
12. Heyward VH, Stolarczyk LM, editors. Skinfold method. In: Applied Body Composition Assessment. Champaign, IL: Human Kinetics; 1996:21-43.

13. Jackson AS, Pollock ML. Generalized equations for predicting body density of men. Brit J Nutr. 1978;40(3):487-504.

14. Jackson AS, Pollock ML, Ward A. Generalized equations for predicting body density of women. Med Sci Sport Exerc. 1980;12(3):175-181.

15. Siri WE. Body composition from fluid spaces and density: analysis of methods. In: Brožek J, Henschel A, editors. Techniques for Measuring Body Composition. Washington, DC: National Academy of Sciences - National Research Council; 1961:223-244.

16. Wasserman K, Hansen JE, Sue DY, Stringer WW, Whipp BJ. Principles of Exercise Testing and Interpretation, 4th ed. Philadelphia: Lippincott Williams \& Wilkins; 2005.

17. Bangsbo J. The physiology of soccer - with special reference to intense intermittent exercise. Acta Physiol Scand Suppl. 1994;619:1-155.

18. Reilly T. Energetics of high-intensity exercise (soccer) with particular reference to fatigue. J Sports Sci. 1997;15(3):257-263.

19. Esposito F, Impellizzeri FM, Margonato V, Vanni R, Pizzini G, Veicsteinas A. Validity of heart rate as an indicator of aerobic demand during soccer activities in amateur soccer players. Eur J Appl Physiol. 2004;93(1-2):167-172.

20. Esteve-Lanao J, Foster C, Seiler S, Lucia A. Impact of training intensity distribution on performance in endurance athletes. J Strength Cond Res. 2007;21(3):943-949.

21. Seiler S, Haugen O, Kuffel E. Autonomic recovery after exercise in trained athletes: intensity and duration effects. Med Sci Sports Exerc. 2007;39(8):1366-1373.

22. Crisafulli A, Vitelli S, Cappai I, et al. Physiological responses and energy cost during a simulation of a Muay Thai boxing match. Appl Physiol Nutr Metab. 2009;34(2):143-150.

23. Zehr EP, Sale DG. Oxygen uptake, heartrate and blood lactate responses to the Chito-Ryu Seisan kata in skilled karate practitioners. Int J Sports Med. 1993;14(5):269-274.

24. Campos FA, Bertuzzi R, Dourado AC, Santos VG, Franchini E. Energy demands in taekwondo athletes during combat simulation. Eur J Appl Physiol. 2012;112(4):1221-1228.

25. Bridge CA, Jones MA, Hitchen P, Sanchez X. Heart rate responses to Taekwondo training in experienced practitioners. J Strength Cond Res. 2007;21(3):718-723.

26. Helgerud J, Høydal K, Wang E, et al. Aerobic high-intensity intervals improve VO2 max more than moderate training. Med Sci Sports Exerc. 2007;39(4):665-671.
27. Laursen PB, Shing CM, Peake JM, Coombes JS, Jenkins DG. Interval training program optimization in highly trained endurance cyclists. Med Sci Sports Exerc. 2002;34(11):1801-1807.

28. Sharratt MT, Taylor AW, Song TM. A physiological profile of elite Canadian freestyle wrestlers. Can J Appl Sport Sci. 1986;11(2): 100-105.

29. Beneke R, Beyer T, Jachner C, Erasmus J, Hütler M. Energetics of karate kumite. Eur J Appl Physiol. 2004;92(4-5):518-523.

30. Chiodo S, Tessitore A, Cortis C, et al. Effects of official Taekwondo competitions on all-out performances of elite athletes. J Strength Cond Res. 2011;25(2):334-339.

31. Shaw DK, Deutsch DT. Heart rate and oxygen uptake response to performance of karate kata. J Sports Med Phys Fitness. 1982;22(4): $461-468$.

32. Toskovic NN, Blessing D, Williford HN. The effect of experience and gender on cardiovascular and metabolic responses with dynamic Tae Kwon Do exercise. J Strength Cond Res. 2002;16(2):278-285.

33. Toner MM, Glickman EL, McArdle WD. Cardiovascular adjustments to exercise distributed between the upper and lower body. Med Sci Sports Exerc. 1990;22(6):773-778.

34. Glaister M, Stone MH, Stewart AM, Hughes M, Moir GL. The influence of recovery duration on multiple sprint cycling performance. J Strength Cond Res. 2005;19(4):831-837.

35. Buchheit M, Papelier Y, Laursen PB, Ahmaidi S. Noninvasive assessment of cardiac parasympathetic function: postexercise heart rate recovery or heart rate variability? Am J Physiol Heart Circ Physiol. 2007;293(1):H8-H10

36. Vissing J. Muscle reflex and central motor control of neuroendocrine activity, glucose homeostasis and circulation during exercise. Acta Physiol Scand Suppl. 2000;647:1-26.

37. Rowell LB, O'Leary DS. Reflex control of the circulation during exercise: chemoreflexes and mechanoreflexes. J Appl Physiol. 1990; 69(2):407-418.

38. Buchheit M, Duché P, Laursen PB, Ratel S. Postexercise heart rate recovery in children: relationship with power output, blood $\mathrm{pH}$, and lactate. Appl Physiol Nutr Metab. 2010;35(2):142-150.

39. Lewis DA, Kamon E, Hodgson JL. Physiological differences between genders. implications for sports conditioning. Sports Med. 1986;3(5):357-369.

40. Sheel AW, Richards JC, Foster GE, Guenette JA. Sex differences in respiratory exercise physiology. Sports Med. 2004;34(9):567-579.
Open Access Journal of Sports Medicine

\section{Publish your work in this journal}

Open Access Journal of Sports Medicine is an international, peer-reviewed, open access journal publishing original research, reports, reviews and commentaries on all areas of sports medicine. The manuscript management system is completely online and includes a very quick and fair peer-review system.

\section{Dovepress}

Visit http://www.dovepress.com/testimonials.php to read real quotes from published authors. 